J. Clin. Chem. Clin. Biochem.

Vol. 16, 1978, pp. $567-570$

\title{
Abhängigkeit der Konzentrationen von Kreatinin und Harnstoff im Serum von der Tageszeit bei normaler und eingeschränkter Nierenfunktion ${ }^{1}$ )
}

\author{
Von E. Knoll, H. Wisser und F. C. Rebel \\ Abteilung für Klinische Chemie des Robert-Bosch-Kranken/hauses, Stultgart
}

(Eingegangen am 23. Januar/28. Juni 1978)

Zusammenfassung: Die Tagesschwankungen der Konzentrationen von Kreatinin, Harnstoff und Cortisol im Serum wurden bei 7 Patienten ohne eine Nieren- oder Muskelerkrankung und 8 Patienten mit eingeschränkter Nierenfunktion (Kreatinin-Clearance $<40 \mathrm{ml} / \mathrm{min}$ ) untersucht. Sowohl Kreatinin als auch Harnstoff zcigen $\mathrm{kcinen}$ circadianen Rhythmus; die Tagesscliwankungen liegen im Bereich der methodischen Streuung. Das Serum-Cortisol zeigt den bekannten circadianen Rhythmus mit großen Amplituden.

\section{Dependence of the serum concentrations of creatinine and urea on the time of day, with normal and impaired kidney function}

Summary: Daily variations in the serum concentrations of creatinine, urea and cortisol were studied in 7 patients without kidney or muscle disease, and in 8 patients with impaired kidncy function (creatinine clearance $<40 \mathrm{ml} / \mathrm{min}$ ). Neither creatinine nor urea showed a circadian rhy thm; the daily variations lay within the limits of the methodological scatter. Serum cortisol showed its known circadian rhythm in high amplitude.

\section{Einführung}

Die Kreatininkonzentration im Serum und die KreatininClearance sind wichtige Parameter bei der Abklärung einer Niereninsuffizienz. Die Frage nach einer eventuellen Abhängigkeit des Serumkreatinins von der Tageszeit ist deshalb von Bedeutung. Bei einem stark ausgeprägten Tagesrhy thmus - wie etwa beim Cortisol - würde man je nach den Zeitpunkten der Blutentnahme und der Bestimmung der Referenzwerte zu falsch positiven bzw. falsch negativen Ergebnissen kommen. Ein großer Teil der Untersuchungen zur Tageszeitabhängigkeit klinischchemischer Parameter wurde unter standardisierten $\mathrm{Be}$ dingungen (wie z. B. totale Nahrungskarenz, eingeschränkte körperliche Aktivität) durchgeführt, so daß diese Ergebisse nicht ohne weiteres auf Kliniksbedingungen übertragen werden können. Außerdem sind die bisher ermittel ten Versuchsergebnisse bezüglich des Kreatinins recht widersprüchlich (1-5). In der vorliegenden Studie wurde deshalb die Tagesperiodik der Kreatinin- und Harnstoffkonzentration im Serum bei Patienten mit normaler und eingeschränkter Nierenfunktion untersucht. Gleichzeitig wurde die Cortisolkonzentration mitbestimmt, um einen unabhängigen Parameter mit be-

\footnotetext{
1) Diese Arbeit wurde unterstützt aus Mitfeln der Robert-BoschStiftung, Stuttgart.
}

kannter ausgeprägter Rhythmik zu haben. Eine eventuell vorhandene Rhythmik der Harnstoff-oder Kreatininkonzentration sollte dazu bezüglich Schwingungsbreiten und Phase in Relation gesetzt werden. Außerdem sollte durch die Bestimmung der Cortisolrhythmik die zeitliche und technische Durchführung der Blutentnahme überprüft werden.

\section{Versuchsbeschreibung}

7 Klinikpatienten mit normalen Kreatininwerten ( 2 Frauen und 5 Männcr) im Alter von 24-66 Jahren mit den klinischen Diagnosen vegetative Dystonie (2), Ulcus duodeni (2), chronische Bronchitis (2) und Trigeminusncuralgic (1) wurden in die Untersuchung einbezogen. Eine zweite Gruppe umfads te 8 Patienten (2 Frauen und 6 Männer) mit erhöhten Kreatininwerten (fortgeschrittene Nephritis (1), chronische Glomerulonephritis (2), Arterio-Arteriolosklerose der Nieren bei allgenleiner Gefäissklerose (3) und diabetische Glomerulosklerose (2)) im Alter von 20-60 Jahuren. Die Kreatinin-Clearance-Werte lagen zwischen 10 und $40 \mathrm{ml} / \mathrm{min}$. Alle Patienten wurden erst nach 8-tägigem Krankenhausaufenthalt in die Studie aufgenommen, so daß sic an die Krankenhausroutine adaptiert waren. Während der Untersuchung konnten dic Probanden normale Klinikkost zu sich nchmen und nach Belieben aufstehen. Dic Schlafzcit lag zivischen 22.00 und 6.00 Uhr, wobci dic Patienten zur Blutentnahme, dic über einen in der Kubitalvene liegenden Katheter crfolgte, kurz geweckt wurden. Beginnend um 8.00 Uhr morgens wurde dè Patienten über cinen Zeitraum von 24 Stunden alle 3 Stunden etwa $5 \mathrm{ml}$ Blut ont nommen. Die Blutproben wurden sofort zentrifugiert und das gewonnene Serum bei $-30^{\circ} \mathrm{C}$ bis zur Analyse cingefroren. 


\section{Methoden}

Die Kreatininbestimmung im Serum wurde mit der FullererdeMethode ohne Enteiweißung des Serums durchgeführt (6). Die Zuverlässigkeitskriterien dieser Methode sind in der zitierten Arbeit detailliert beschrieben, so daß auf eine nochmalige Wiedergabe verzichtet wird. Dieses Verfahren hat eine gute Präzision, verbunden mit einer hohen Spezifität, womit es gelingt, das „wahre Kreatinin" zu bestimmen. So können die bei Verwendung einer unspezifischen Bestimmungsmethode evtl. auftretenden Tagesschwankungen des ,,scheintaren Kreatinins“ - verursacht durch schwankende Serumkonzentrationen von Pseudokreatininen - vermieden werden.

Der Harnstoff wurde mit der Urease-GlutamatdehydrogenaseMethode mit dem ENI-Fast-Analyzer $\left.{ }^{2}\right)(7,8)$ bestimmt. Die Bestimmung des Cortisols erfolgte durch eine kompetitive Proteinbindungsmethode (9).

\section{Ergebnisse und Diskussion}

In Tabelle 1 sind die Ergebnisse der Präzisionskontrolle der 3 gemessenen Parameter zusammengefaßt. Die Variationskoeffizienten der Streuung in der Serie betragen für die Harnstoff- und Kreatininbestimmung 2,3 bzw. 2,4\% und für das Cortisol 6,2\%, für die Streuung von Tag zu Tag in der gleichen Reihenfolge der Parameter 4,2\%, $4,5 \%$ und $10,6 \%$. Da die Patientenproben in Serie analysiert wurden, sind zur Abschätzung des methodischen Einflusses die Variationskoeffizienten für die Streuung in der Serie zu berücksichtigen. Die methodische Streuung der Harnstoff- und Kreatininbestimmung ist so niedrig, daß auch eine nur geringgradig ausgeprägte Tageszeitabhängigkeit von ihr nicht verwischt werden kann. In den Abbildungen 1 und 2 sind von den beiden Patientengruppen die Tagesverläufe des Kreatinins und des Harnstoffs wiedergegeben.

Hierbei sind die Abweichungen in $\mu \mathrm{mol} / \mathrm{l}$ (Kreatinin) bzw. $\mathrm{mmol} / \mathrm{l}$ (Harnstoff) vom jeweiligen Tagesmittel einer Versuchsperson als Funktion der Tageszeit aufgetragen. Aus den Abbildungen ist zu ersehen, daß die Tagesschwan-

Tab. 1. Ergebnis der Präzisionskontrolle der 3 Parameter Kreatinin, Harnstoff und Cortisol.

\begin{tabular}{|c|c|c|c|}
\hline \multirow[b]{2}{*}{ Bestandteil } & \multirow{2}{*}{$\begin{array}{l}\text { Statistische } \\
\text { Kenngröße }\end{array}$} & \multicolumn{2}{|c|}{ Streuung } \\
\hline & & $\begin{array}{l}\text { i. d. Serie } \\
\text { aus Doppelbest. }\end{array}$ & $\begin{array}{l}\text { von Tag } \\
\text { zu Tag }\end{array}$ \\
\hline Kreatinin & $\begin{array}{l}\bar{x}(\mu \mathrm{mol} / 1) \\
\text { s }(\mu \mathrm{mol} / 1) \\
V(\%) \\
n\end{array}$ & $\begin{array}{c}149,5 \\
3,6 \\
2,4 \\
20 \text { Doppelbest. }\end{array}$ & $\begin{array}{c}149,5 \\
6,3 \\
4,2 \\
20 \text { Einzelbest. }\end{array}$ \\
\hline Harnstoff & $\begin{array}{l}\bar{x}(\mathrm{mmol} / \mathrm{l}) \\
\mathrm{s}(\mathrm{mmol} / \mathrm{l}) \\
\mathrm{V}(\%)\end{array}$ & $\begin{array}{c}13,1 \\
0,3 \\
2,3 \\
20 \text { Dopnelbest }\end{array}$ & $\begin{array}{c}13,1 \\
0,59 \\
4,5 \\
20 \text { Einzelbest }\end{array}$ \\
\hline Cortisol & $\begin{array}{l}\bar{x}(\mathrm{nmol} / \mathrm{l}) \\
\mathrm{s}(\mathrm{nmol} / \mathrm{l}) \\
\mathrm{V}(\%) \\
\mathrm{n}\end{array}$ & $\begin{array}{c}329,9 \\
20,1 \\
6,1 \\
22 \text { Doppelbest. }\end{array}$ & $\begin{array}{l}329,6 \\
35 \\
10,6 \\
24 \text { Einzelbest. }\end{array}$ \\
\hline
\end{tabular}

2) Electro Nucleonics Europe, Stuttgart.

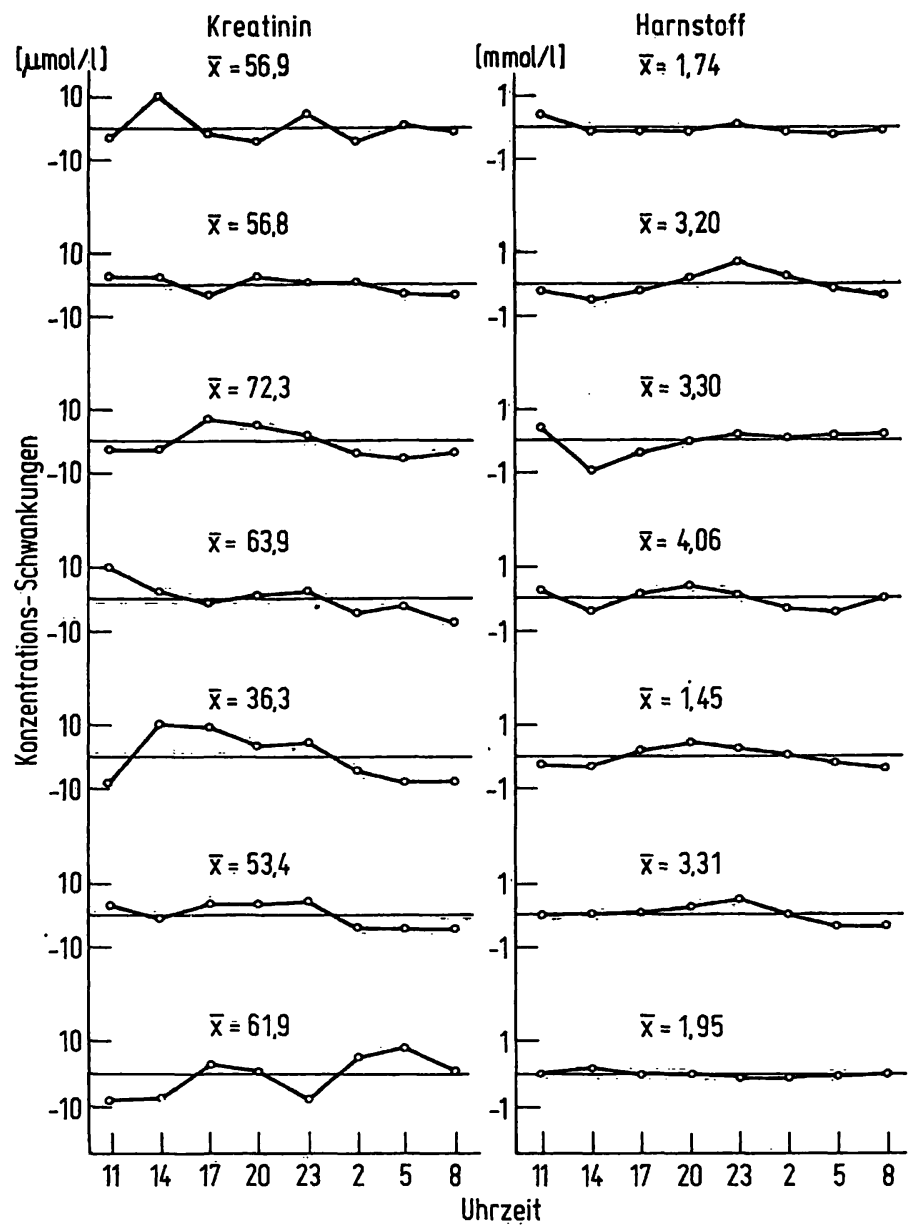

Abb. 1. Tagesverläufe der Konzentrationen von Kreatinin und Harnstoff in Serum bei den Patienten mit normaler Nierenfunktion.

kungen dieser beiden Parameter sehr gering sind, insbesondere in der Patientengruppe mit normaler Nierenfunktion. Die maximalen Schwankungen in dieser Gruppe betragen $\pm 10 \mu \mathrm{mol} / 1 \mathrm{Kreatinin}$ bzw. $\pm 1 \mathrm{mmol} / 1$ Harnstoff. Des weiteren läßt sich aus den beiden Abbildungen entnehmen, daß für beide Bestandteile bețrächtliche interindividuelle Unterschiede bestehen, d.h. die Tagesverläufe sind bei den einzelnen Versuchspersonen sehr unterschiedlich. Es wäre interesșant zu wisssen, inwieweit die intraindividuellen Tagesschwankungen zeitlich reproduzierbar sind. Hierzu müßte man Versuchspersonen mehrere Tage hintereinander untersuchen, was sich jedoch an Klinikpatienten kaum durchführen läßt; diese Untersuchungen müßten an freiwilligen Versuchspersonen durchgeführt werden.

Bezüglich der Gleichwerte (= Tagesmittelwerte) bestehen ebenfalls große interindividuelle Unterschiede, insbesondere in der Gruppe der Patienten mit eingeschränkter Nierenfunktion. Um zu einer einheitlichen Darstellung zu kommen, werden bei jeder Versuchsperson die prozentualen Abweichungen der Einzelwerte vom jeweiligen Gleichwert berechnet. Dann werden innerhalb der beiden Patientengruppen für die einzelnen Abnahmezeiten die prozentualen Abweichungeñ gemittelt. 


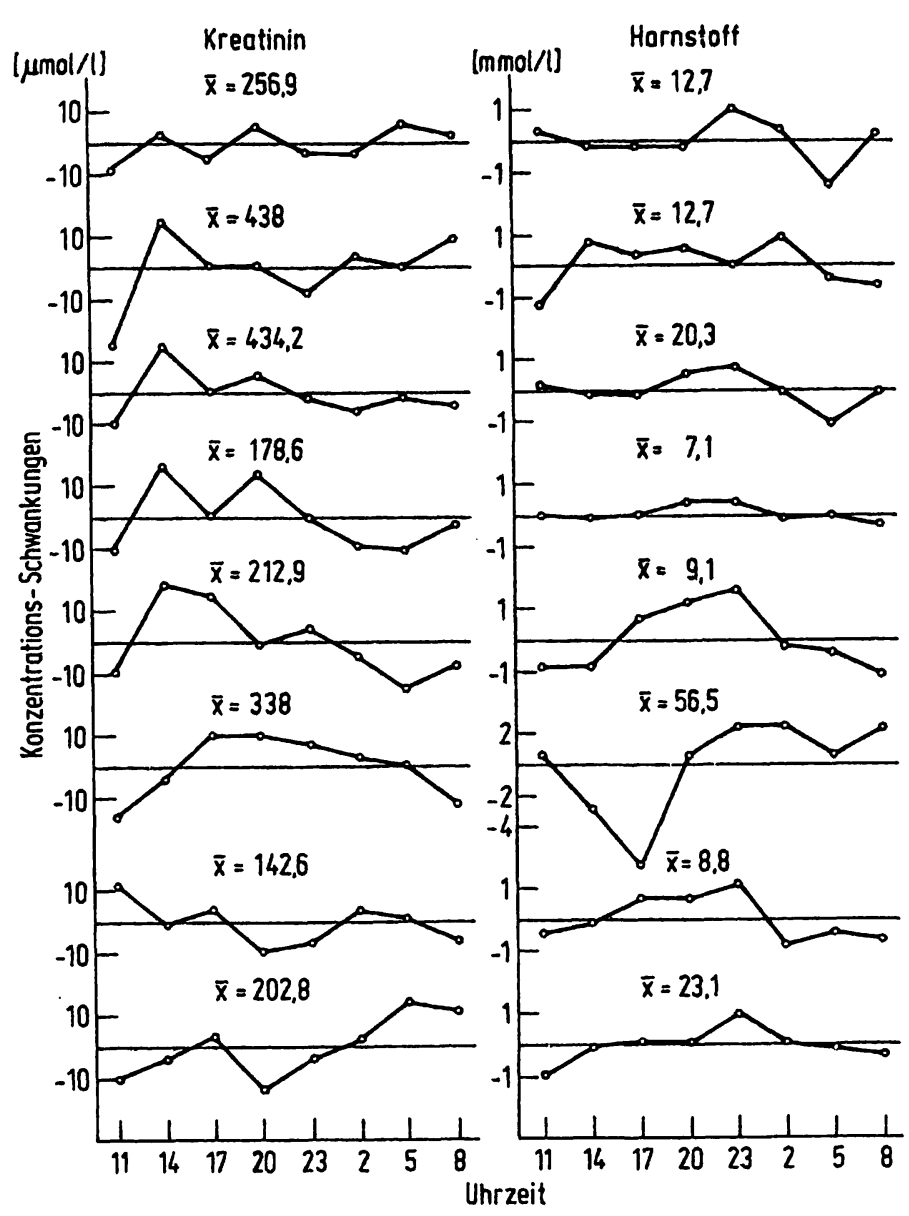

Abb. 2. Tagesverläufe der Konzentrationen von Kreatinin und Harnstoff in Serum bei den Patienten mit eingeschränkter Nierenfunktion.

In Abbildung 3 sind die Ergebnisse für die 3 gemessenen Parameter Kreatinin, Harnstoff und Cortisol für die beiden Gruppen dargestellt.

Das Kreatinin zeigt bei den Versuchspersonen mit normalen Nierenfunktion nur geringe Tagesschwankungen mit Maxima um 14.00 und 17.00 Uhr und dem Minimum um 8.00 Uhr. Die Amplitude (= Differenz zwischen Maximum und dem Gleichwert) beträgt.etwa $6-7 \%$. Die Differenż zwischen den beiden Extrema ist statistisch nicht signifikant (Wilcoxon-Test für Paardifferenzen, $\alpha=0,05$ ) und auch klinisch nicht relevant, wie sich aus Abbildung 1 aus den Absolutwerten ersehen läßt. Bei den Patienten mit eingeschränkter Nierenfunktion sind die prozentualen Abweichungen vom Gleichwert infolge des wesentlich höheren Gleichwertes noch geringer. Das Maximum liegt bei 14.00 Uhr mit $+2,9 \%$ und das Minimum bei 11.00 Uhr mit $-2,9 \%$, auch hier ist die Differenz nicht signifikant (gleicher Test, gleiches Testniveau wie oben).

Der Harnstoff zeigt bei den Probanden mit normaler Nierenfunktion etwas größere und häufigere Schwankungen als das Kreatinin. Dies dürfte sicherlich auf die stärkere Abhängigkeit des Serum-Harnstoffs von der Nahrungszufuhr zurückzuführen sein. Dem Maximum um 23.00 $\mathrm{Uhr}$ folgt das Minimum um 5.00 Uhr, und

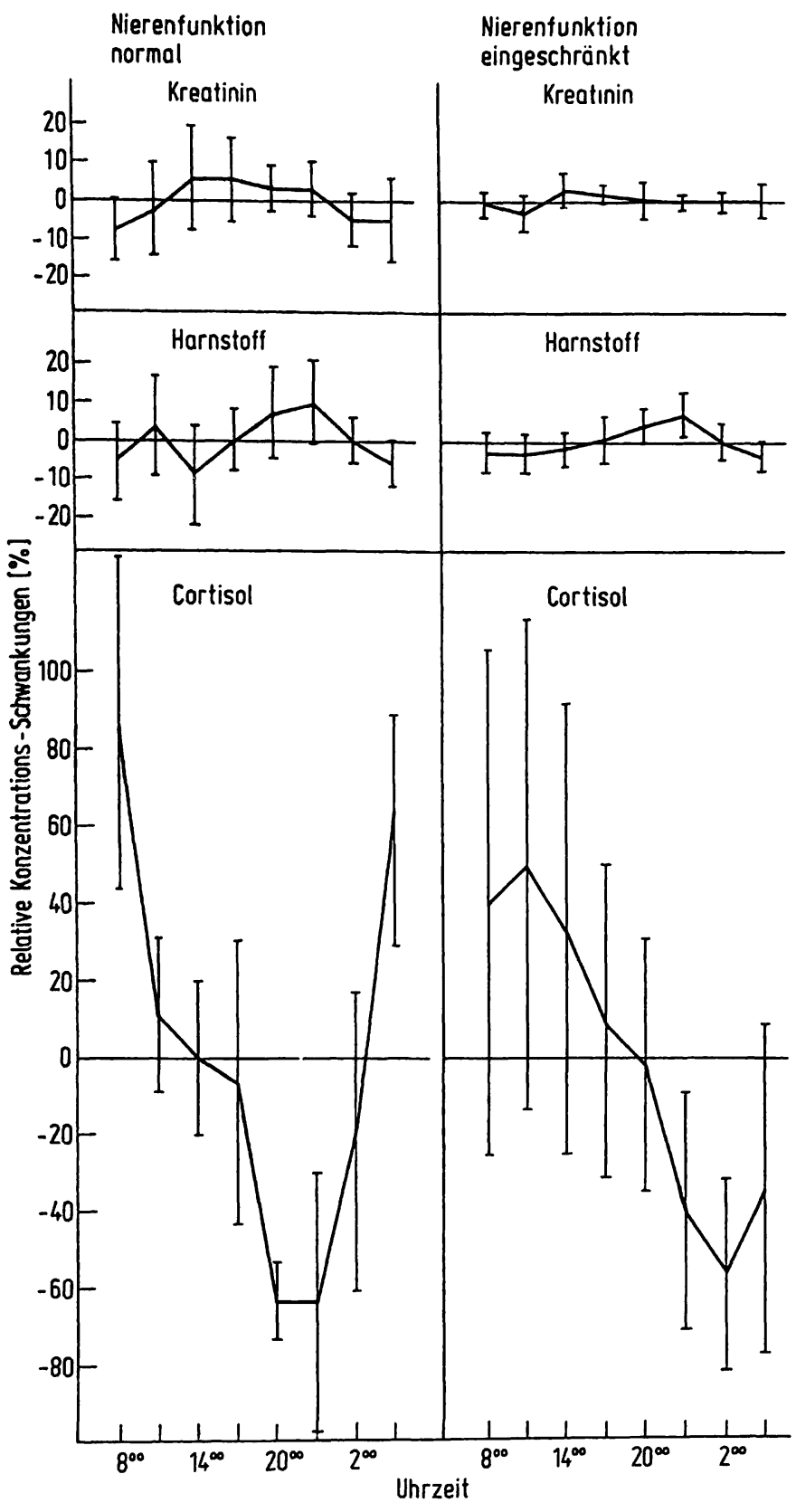

Abb. 3. Tagesschwankungen der Konzentrationen von Kreatinin, Harnstoff und Cortisol in Serum als prozentuale Abweichungen vom Gleichwert.

nach einem kleinen Anstieg um 11.00 Uhr folgt um 14.00 Uhr ein weiteres Minimum.

Ähnlich wie beim Kreatinin werden auch beim Harnstoff bei den Patienten mit eingeschränkter Nierenfunktion die relativen Abweichungen vom Gleichwert geringer. Dem Maximum um 23.00 Uhr von $+7,1 \%$ folgt ein breites Minimum von $5.00 \mathrm{Uhr}-11.00 \mathrm{Uhr}$, das um $-3 \%$ schwankt. Die Tagesschwankungen sind bei beiden Gruppen so gering, daß sie klinisch nicht von Bedeutung sind.

Das in den gleichen Proben gemessene Cortisol zeigt unabhängig vom Zustand der Nierenfunktion das bekannte charakteristische Tagesprofil mit großen Amplituden. Das Maximum ist in den frühen Morgenstunden, in denen die 
meisten Sekretionsphasen liegen und das Minimum in der Nacht.

Die Konzentration des Kreatinins im Serum wurde lange Zeit als konstant angesehen und unabhängig von alimentären Einflüssen. Stamm (1) fand in einer Untersuchung an fastenden Probanden starke Tagesschwankungen des Kreatinins und Harnstoffs. Aus 24 gesunden Männern gemittelt war das Maximum der Kreatininkonzentration in den Nachtstunden zwischen 2.00 Uhr und 5.00 Uhr bei etwa $1,3 \mathrm{mg} / 100 \mathrm{ml}$, das Minimum um $8.00 \mathrm{Uhr}$ bei $0,85 \mathrm{mg} / 100 \mathrm{ml}$. $\mathrm{Zu}$ genau dem entgegengesetzten Ergebnis kamen Pasternack \& Kuhlbäck (2). Sowohl bei Normalpersonen als auch bei Patienten mit Muskelatrophie fanden sie im Verlauf des Tages ein Ansteigen der Kreatinin-Konzentration bis zu einem Maximum um 19.00 Uhr, das etwa $30 \%$ über dem um 7.00 Uhr lag. Bei fastenden Normalpersonen verschwanden aber diese Schwankungen fast vollständig. Letztere Autoren nahmen den Einfluß der Nahrungszufuhr als Ursache der Tages- schwankungen an. Unsere Ergebnisse sprechen gegen eine solche Abhängigkeit, da bei unserer Untersuchung die Versuchspersonen nach Belieben èssen und trinken durften. Trotzdem zeigt sich über die gesamten 24 Stunden keine signifikante Abweichung der Kreatinin-Konzentration vom Gleichwert.

Steinbach et al. (5) fanden für das Serum-Kreatinin sogar eine 2-gipfelige circadiane Wellenform mit Maxima um 18.00 und 6.00 Uhr und Minima um 10.00 und 2.00 Uhr. Allerdings verwendeten diese Autoren ein unspezifisches Verfahren zur Kreatininbestimmung, so daß eine Beeinflussung der Kreatininbestimmung durch Störsubstanzen, die ihrerseits Tagesschwankungen unterliegen, nicht auszuschließen ist. Statland et al. (4) an einer Gruppe von 11 jungen Männern und Buchsbaum et al. (3) an 4 freiwilligen normalen Erwachsenen fanden in Übereinstimmung mit unseren Ergebnisssen an Klinikpatienten keine statistisch signifikanten Tagesschwankungen des SerumKreatinins.

\section{Literatur}

1. Stamm, D. (1967), Verh. Deutsch. Ges. Inn. Med., 984-989.

2. Pasternack, A. \& B. Kuhlbäck (1971), Scand. J. Clin. Lab. Invest. 27, 1-7.

3. Buchsbaum, M. \& E. K. Harris (1971), J. Appl. Physiol. 30, 27-35.

4. Statland, B. E., P. Winkel \& H. Bokelund (1973), Clin. Chem. $19,1374-1379$.

5. Steinbach, G., M. Hilfenhaus, H. v. Mayersbach \& W. Poesche (1976), Arch. Toxicol. 36, 317-325.
6. Knoll, E. \& H. Wisser (1973), diese Z. 11, 411-414.

7. Eisenwiener, H. G. (197.6), Ärztl. Lab. 22, 53-59.

8. Gutmann, I. \& H. U. Bergmeyer (1974), in Bergmeyer, H. U. ed.: Methoden der enzymatischen Analyse 3. Aufl. Bd. II, Verlag Chemie Weinheim, 1839-1846.

9. Köbberling, J. \& A. v. z. Mühlen (1972), diese Z. 10, 67-73.

Dr. rer. nat. E. Knoll Abteilung für Klinische Chemie Robert-Bosch-Krankenhaus Auerbachstr. 110 7000 Stuttgart 50 